\title{
Vertebral compression fractures in acute lymphoblastic leukaemia and remodelling after treatment
}

\author{
N A Pandya, S T Meller, D MacVicar, A A Atra, C R Pinkerton
}

\author{
Abstract \\ Three children, aged 7-10 years, with \\ acute lymphoblastic leukaemia presented \\ with back pain, along with a mild kypho- \\ sis. Collapse of the vertebral bodies at \\ multiple levels was shown on imaging. \\ Chemotherapy resulted in pain resolution \\ and spontaneous remodelling of the verte- \\ brae. \\ (Arch Dis Child 2001;85:492-493)
}

Keywords: acute lymphoblastic leukaemia; compression fractures; osteopenia; vertebral collapse

Bone and joint pain may be a presenting symptom in $25 \%$ of patients with acute leukaemia, ${ }^{1}$ whereas generalised osteopenia and vertebral complications are less common. ${ }^{2}$

We report three children in whom back pain associated with vertebral compression and collapse were presenting features of childhood acute lymphoblastic leukaemia (ALL); radiological remodelling with return of function occurred with remission.

\section{Case 1}

A 7 year old boy presented with generalised joint and back pain, widespread lymphadenopathy, a kyphosis of the thoracic spine, and hepatomegaly. Haemoglobin was $71 \mathrm{~g} / \mathrm{l}$, leucocyte count $1.8 \times 10^{9}$, and platelet count $73 \times$ $10^{9}$.

Radiology revealed osteopenia and vertebral compression fractures throughout the thoracic and lumbar spine. Magnetic resonance imaging (MRI) showed a diffuse alteration of signal in the marrow cavities (fig 1 ).

A diagnosis of ALL (L1) was made on bone marrow aspirates. Treatment was commenced and subsequent remodelling of the bone and vertebrae was observed and documented (fig 2). A mild kyphosis persists six years after presentation.

\section{Case 2}

A 9 year old girl presented with a two month history of progressive low back pain. Initial haematology was normal; however, a repeat blood count two months later revealed a haemoglobin of $99 \mathrm{~g} / \mathrm{l}$, leucocyte count of $2.6 \times$ $10^{9}$, and platelet count of $53 \times 10^{9}$, along with circulating blasts on peripheral blood films. Serum calcium concentration was $2.85 \mathrm{mmol} / 1$ (normal range $2.2-2.7 \mathrm{mmol} / \mathrm{l}$ ), phosphate $1.65 \mathrm{mmol} / 1$ (1.2-1.65 mmol/1), magnesium $0.92 \mathrm{mmol} / \mathrm{l}(0.6-0.9 \mathrm{mmol} / \mathrm{l})$, and alkaline phosphatase $177 \mathrm{U} / 1$ (145-420 U/1).

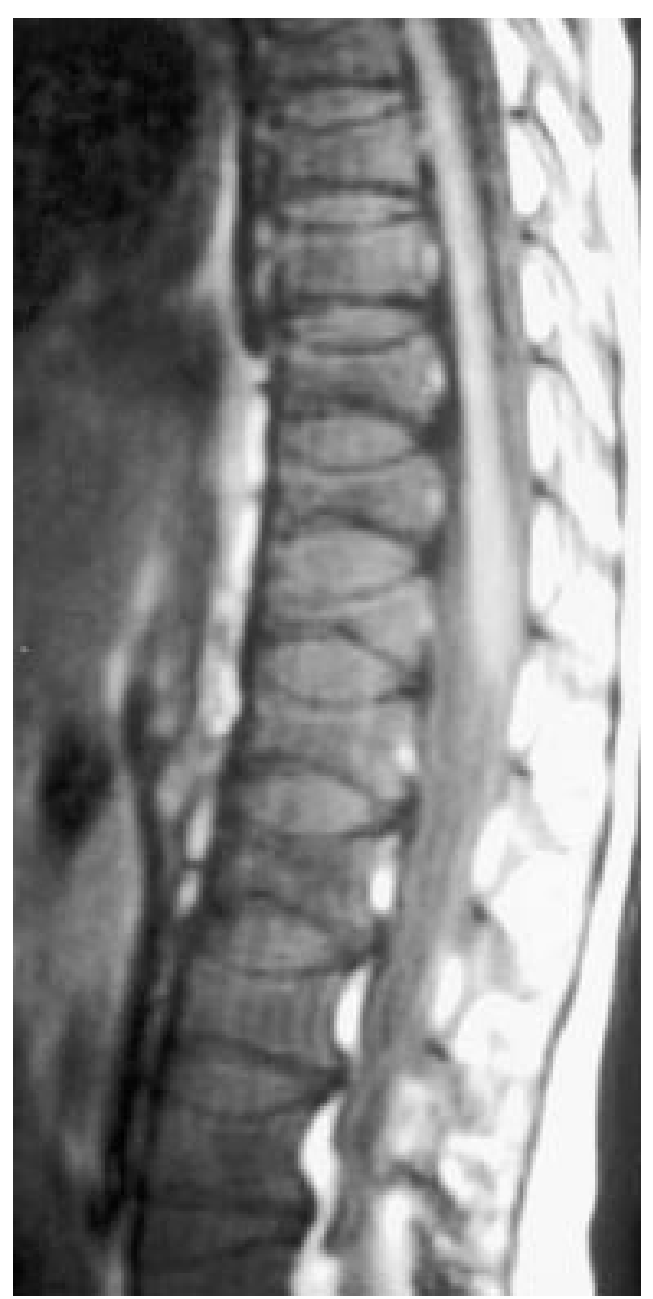

Figure $1 \quad$ T1 weighted sagittal images of the spine showing diffuse homogeneous signal from the vertebral bone marrow cavities, indicating a diffuse pathology as the cause of the multiple compression fractures. There is no evidence of spinal cord compression.

Clinical examination showed hepatosplenomegaly. Bone marrow aspirates confirmed ALL (L2). Radiology showed compression fractures of the vertebral bodies in the lower thoracic region. Persistently raised calcium concentrations were treated with bisphosphonate infusion. A relapse was signalled by bone pain, normal biochemistry, and osteopenic vertebrae without collapse (the latter confirming that some remodelling had occurred during remission) 16 months after completion of initial treatment.

\section{Case 3}

A 10 year old girl presented with a three month history of increasing lower back pain. Clinical examination was normal. MRI showed a 


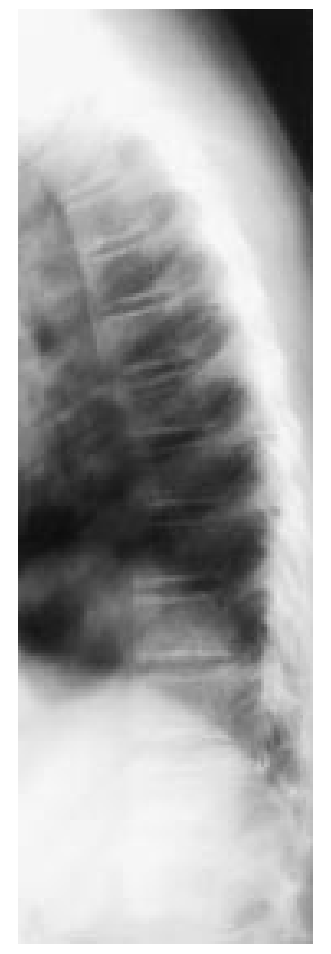

Figure 2 Following successful treatment, the lateral radiograph of the thoracic spine has returned to normal, with remodelling and reconstitution of bony texture. diffuse homogeneous abnormal signal from the marrow cavities of the vertebral bodies with compression fractures in the lower thoracic region. Haemoglobin was $114 \mathrm{~g} / 1$, platelets 102 $\times 10^{9}$, leucocyte count $1.6 \times 10^{9}$, and neutrophils $0.4 \times 10^{9}$. Bone marrow aspirate showed infiltration with L2 lymphoblasts.

She continues to remain pain free and in remission on treatment.

\section{Discussion}

Radiological evidence of demineralisation during the course of leukaemia can be caused by disease, inactivity, steroids, or other antileukemic drugs, or to abnormalities in mineral homoeostasis.

Spinal involvement may be a presenting feature despite normal peripheral blood counts. ${ }^{45}$

The use of MRI in the diagnosis of bone marrow disease in children is complicated by the change that takes place in the relative proportions of haematogenous and fatty marrow. In the context of bony pain with vertebral collapse, the finding of diffuse low signal in the vertebral marrow cavities is a strong indicator of a systemic disease affecting the marrow. Steroid therapy causing vertebral collapse should leave the marrow signal in other vertebrae unchanged. ${ }^{6}$

Diagnosis was delayed up to three months in all three patients. Case 2 had hypercalcaemia at presentation. Biphosphonate decreases bone pain and helps to prevent complications of progressive vertebral collapse. ${ }^{7}$

Vertebral compression fractures seldom cause neurological compromise, and they appear to remodel as the underlying disease is treated. ALL which presents with leucopenia, severe and constant pain, and a long interval between the onset of symptoms and diagnosis, carries an unfavourable outlook. ${ }^{8}$ The significance of bone involvement at diagnosis is uncertain. Heinrich et al suggested that duration of symptoms prior to diagnosis influences outcome rather than the nature of skeletal radiographic abnormalities. ${ }^{9}$

\section{CONCLUSION}

There should be a high index of suspicion in patients, particularly if there is worsening back pain with the associated radiographic findings of vertebral compression fractures and an abnormal bone marrow signal on MRI.

Antileukemic treatment usually results in rapid symptomatic relief as well as radiographic evidence of bony remodelling.

1 Vassilipoulou-Selin R, Ramirez I. Severe osteopenia and vertebral compression fractures after complete remission in an adolescent with acute leukaemia. Am $\mathcal{f} \mathrm{Hematol}$ 1992;39:142-3.

2 Cohn SL, Morgan ER, Mallette LE. The spectrum of metabolic bone disease in lymphoblastic leukaemia. Cancer 1987;59:346-50.

3 Newman AJ, Melhorn DK. Vertebral compression in childhood leukemia. Am f Dis Child 1973;125:863-5.

4 Epstein BS. Vertebral changes in childhood leukemia. Radiology 1957;68:65-9.

5 Parker BR, Marglin S, Castellino RA. Skeletal manifestations of leukaemia. Hodgkin's disease and non-Hodgkin's lymphoma. Semin Roentgenol 1980;15:302-15.

6 Moulopoulos LA, Dimopoulos MA. Magnetic resonance imaging of the bone marrow in haematologic malignancies. Blood 1997;90:2127-47.

7 Delmas PD. Bisphosphonates in the treatment of bone diseases. N Engl f Med 1996;335:1836-7.

8 Masera G, Carnelli F, Ferrari M. Prognostic significance of radiological bone involvement in childhood ALL. Arch Dis Child 1977;52:530-3.

9 Heinrich SD, Gallager, D'Warrior R. The prognostic significance of the skeletal manifestations of ALL of childsignificance of the skeletal manifestation
hood. $\mathcal{7}$ Pediatr Orthop 1994;14:105-11. 